\title{
Fabrication of a Flexible Biosensor Based on an Organic Field-effect Transistor for Lactate Detection
}

\author{
Tsukuru Minamiki,*,** Shizuo Tokito, $* * *$ and Tsuyoshi Minami $* \dagger$ \\ *Institute of Industrial Science, The University of Tokyo, 4-6-1 Komaba, Meguro, Tokyo 153-8505, Japan \\ **Biomedical Research Institute, National Institute of Advanced Industrial Science and Technology (AIST), \\ 1-1-1 Higashi, Tsukuba, Ibaraki 305-8566, Japan \\ ***Research Center for Organic Electronics (ROEL), Yamagata University, 4-3-16 Jonan, Yonezawa, \\ Yamagata 992-8510, Japan
}

\begin{abstract}
A novel flexible lactate sensor based on organic field-effect transistors (OFETs) is demonstrated. Because lactate is known as a biomarker for assessing our physical performance, wearable lactate sensors could contribute to the monitoring of human health conditions. The flexible and low-voltage operatable OFET possesses an extended-gate modified with enzymes and an osmium-redox polymer for the lactate detection, meaning that the continuous measurement of lactate levels $(0-10 \mathrm{mM})$ has been successfully achieved. We believe that insight obtained will open up opportunities for applying OFETs in wearable biosensors.
\end{abstract}

Keywords Organic transistors, flexible biosensors, lactate, enzymes, redox polymers

(Received June 25, 2018; Accepted August 13, 2018; Advance Publication Released Online by J-STAGE August 24, 2018)

\section{Introduction}

Biosensor devices for healthcare applications have received significant attention because they enable the analysis of biomolecules ${ }^{1}$ that exist in body fluid such as blood, saliva, urine and sweat. For example, biosensors modified with glucose oxidase or glucose dehydrogenase are some of the notable healthcare tools for diabetics. ${ }^{2}$ Recently, exploratory research of healthcare devices has focused on the real-time monitoring of our health conditions. ${ }^{3}$ If continuous measurements of biomarkers in the human body become possible, more efficient healthcare can be achieved in daily life. However, conventional biosensors based on quartz crystal microbalance (QCM), ${ }^{4}$ surface plasmon resonance (SPR), ${ }^{5}$ or electrochemical (EC) detectors $^{6}$ are limited to use in stationary measurement because these methods generally require large and expensive equipment. Needless to say, the biosensor devices for continuous monitoring of our health conditions should be disposable and wearable.

Because of their flexibility and low-cost processability, organic field-effect transistors ${ }^{7}$ (OFETs) have been widely researched for the development of flexible electronic devices such as rollable displays ${ }^{8}$ and low-cost radio frequency identification (RFID) tags. ${ }^{9}$ Solution-processed OFETs can be adopted for flexible, large-area, and low-cost electronics, ${ }^{10,11}$ suggesting that they are some of more promising devices for wearable sensors. Although some demonstrations of OFETs for sensing applications have been carried out by several of groups, ${ }^{12}$ the research domain of the development of bio/chemical sensors is still in its infancy. Toward this end, we have successfully

$\dagger$ To whom correspondence should be addressed.

E-mail: tminami@iis.u-tokyo.ac.jp demonstrated biosensors based on extended-gate-type OFETs modified with antibodies ${ }^{13-15}$ or enzymes. ${ }^{16,17}$ From the viewpoint of analytical chemistry, OFET-based biosensors should be carefully designed for the accurate detection of biomolecules in aqueous media.

In this paper, we demonstrate a flexible biosensor based on an OFET for lactate detection. Lactate is one of the important biomolecules of metabolism in the human body. ${ }^{18}$ In addition, the lactate level in sweat or blood is well known as a parameter for assessing physical performance of humans in the field of healthcare (e.g. sport science). ${ }^{19,20}$ The continuous measurement of lactate is required for practical exercise management, which could be achieved by wearable biosensors. For instance, Wang et al. reported a wearable biosensor based on an EC method for the real-time monitoring of lactate in sweat. ${ }^{21}$ We also recently developed an OFET on a glass plate connected to an extendedgate electrode modified with a lactate oxidase (LOX) on a plastic film for lactate detection. ${ }^{22}$ Herein, we describe a flexible OFET biosensor, and demonstrate continuous lactate detection in water.

\section{Experimental}

Experimental details are summarized in Supporting Information. To achieve low-voltage and stabilized operation for chemical sensing, the OFET device for the flexible biosensor was designed by employing an extended-gate structure with reliable OFET materials (Fig. 1). ${ }^{23-26}$ In addition, the LOX and a horseradish peroxidase (HRP)/osmium redox polymer complex were utilized as the sensing membrane on the extended-gate. 


\section{Results and Discussion}

The fabricated flexible OFET must work in aqueous media, meaning that the device should be operated under low voltage In addition, stable repeated characteristics are necessary to detect biomolecules with high accuracy and reproducibility. Accordingly, we investigated the basic characteristics (such as

(a)

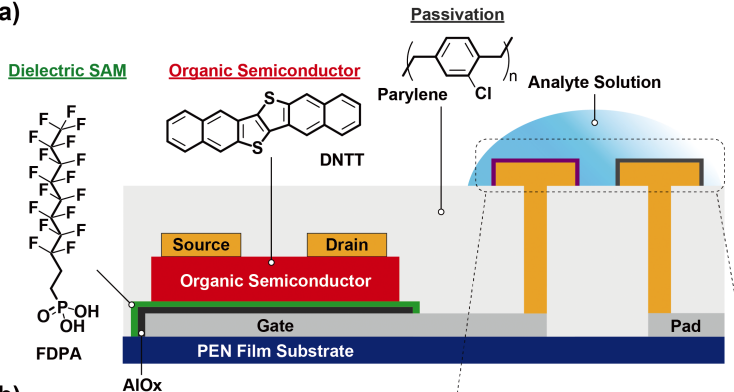

(b) AlOx

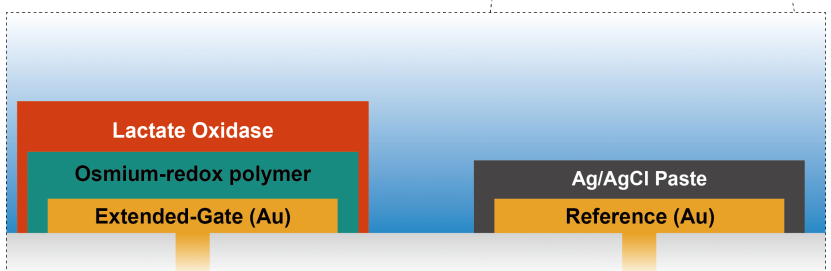

(c)

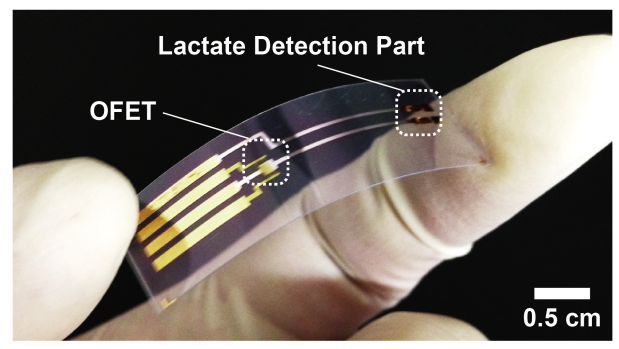

Fig. 1 (a) Schematic structure of the fabricated OFET biosensor device. (b) Details of the detection part. (c) A photograph of the fabricated device. the field-effect mobility and the drain current, etc.) and carried out electrical bias and cycle tests of the fabricated OFET under ambient conditions. With that in mind, each electric parameter of the OFET was estimated by the following equation: ${ }^{27}$

$$
I_{\mathrm{DS}}=(W / 2 L) \mu C\left(V_{\mathrm{GS}}-V_{\mathrm{TH}}\right)^{2}
$$

where $I_{\mathrm{DS}}$ is the drain current, $W$ and $L$ are the channel width and the length (1000 and $50 \mu \mathrm{m}$, respectively), $\mu$ is the fieldeffect mobility, $C$ is the capacitance of the gate dielectric, $V_{\mathrm{GS}}$ is the gate voltage, and $V_{\mathrm{TH}}$ is the threshold voltage, respectively. The $V_{\mathrm{GS}}$ was swept from 0 to $-3 \mathrm{~V}$ while the source-drain voltage $\left(V_{\mathrm{DS}}\right)$ was kept at $-1 \mathrm{~V}$.

As illustrated in the basic characteristics (Fig. S1, Supporting Information), the field-effect mobility in the saturation region was estimated to be $0.10 \mathrm{~cm}^{2} / \mathrm{Vs}$ and the on/off current ratio was $\sim 1000$. More importantly, no hysteresis was observed in the transfer (Fig. S1a) and the output curves (Fig. S1b), indicating that there are no trap states (i.e. physical or chemical issues for unstable operation of the OFET) at the interface between the semiconductor and the dielectric. To evaluate the device stability of the fabricated OFET, we performed DC bias stress and cycle tests. Judging from the observed results of the DC bias stress test on the OFET (Fig. 2a), we concluded that the fabricated device has excellent stability against continuous measurements. Furthermore, the fabricated OFET showed good stability in the cycle test $\left(\Delta I_{\mathrm{DS}} \sim-0.8 \%\right.$ after 60 cycles, Fig. $\left.2 \mathrm{~b}\right)$. It seems that the excellent chemical stability of component materials (DNTT and FDPA) in the OFET endowed us with the above-mentioned stable electric-characteristics. The results obtained here suggest that the fabricated device could be applied in the real-time monitoring of lactate in aqueous media.

To investigate the biosensing ability of the fabricated OFET, we attempted the real-time electrical detection of lactate levels in aqueous media. The gate voltage was applied through a pseudo reference electrode $(=\mathrm{Ag} / \mathrm{AgCl})$. The stable operation was observed in the absence of lactate, while Fig. 3 shows the current response of the OFET biosensor to continuous changes in the lactate level $(0-10 \mathrm{mM})$ in the PBS solution. The observed continuous changes in the drain current mean that the field-effect phenomenon in the fabricated OFET device is affected by the addition of lactate. In other words, the enzymatic reaction (vide infra) on the extended-gate caused such changes. (a)

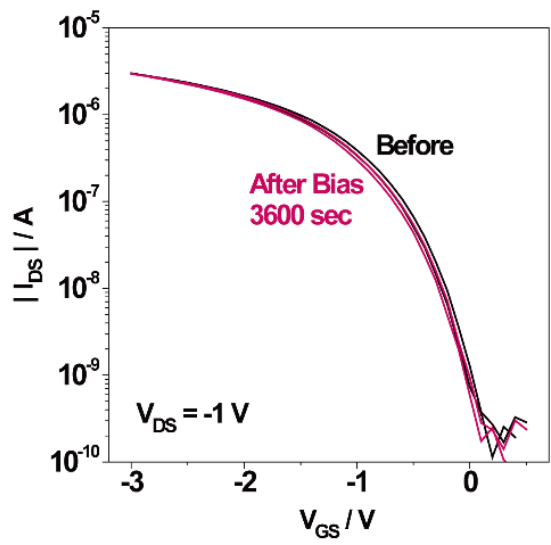

(b)

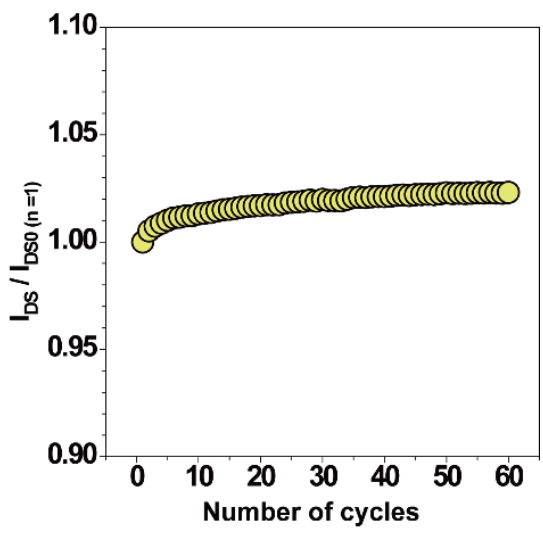

Fig. 2 (a) Transfer characteristics of the fabricated OFET device taken before and after applying a constant bias voltage $\left(V_{\mathrm{GS}}=V_{\mathrm{DS}}=-1.0 \mathrm{~V}\right)$ for $3600 \mathrm{~s}$. (b) Changes in the drain current $\left(I_{\mathrm{DS}}\right)$ of the fabricated OFET device by the cycle test $\left(V_{\mathrm{GS}}=V_{\mathrm{DS}}=-1.0 \mathrm{~V}\right)$. 


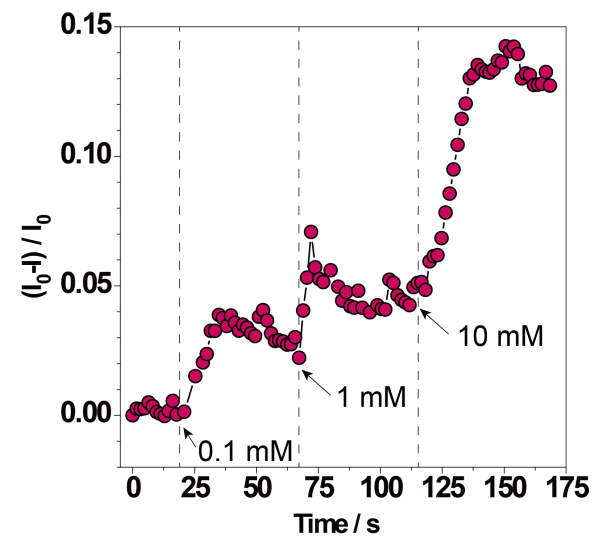

Fig. 3 Time course change of the drain current $\left(I_{\mathrm{DS}}\right)$ with an increase in the concentration of lactate $\left(V_{\mathrm{DS}}=V_{\mathrm{GS}}=-1.0 \mathrm{~V}\right)$.

$$
\begin{aligned}
& \text { Lactate }+\mathrm{H}_{2} \mathrm{O}+\mathrm{O}_{2} \longrightarrow \text { Pyruvate }+\mathrm{H}_{2} \mathrm{O}_{2} \\
& \mathrm{H}_{2} \mathrm{O}_{2}+2 \mathrm{H}^{+}+2 \mathrm{Os}^{\mathrm{II}} \longrightarrow 2 \mathrm{H}_{2} \mathrm{O}+2 \mathrm{Os}^{\mathrm{III}}
\end{aligned}
$$

The first reaction catalyzed by the LOX generates pyruvate and hydrogen peroxide from lactate and oxygen in water. The HRP subsequently reacts with hydrogen peroxide and produces water, followed by the valence changes of the osmium ion in the redox polymer $\left(\mathrm{Os}^{\mathrm{II}} \rightarrow \mathrm{Os}^{\mathrm{III}}\right)$. The above redox reactions result in a decrease of the channel conductance of the OFET through the extended-gate. ${ }^{28,29}$ This is because the channel conductance of the OFET strongly depends on the surface potential on the gate electrode. Importantly, the fabricated device would selectively respond to lactate in biological fluids such as sweat, because no electrical responses to interferent analytes $\left(=\mathrm{MgCl}_{2}\right.$, $\mathrm{CaCl}, \mathrm{NaCl}, p$-cresol, urea, and glucose, which contain in sweat) were observed in the LOX-modified OFET in our previous report. ${ }^{22}$ Moreover, the continuous response range $(0-10 \mathrm{mM})$ was covered within a typical lactate level in sweat (1$100 \mathrm{mM}),{ }^{30,31}$ meaning that the fabricated OFET has sufficient sensitivity for the non-invasive monitoring of lactate. Note that the response range of the fabricated device was higher than that of the previous report $(100-1000 \mathrm{nM})$, because the sensing area for the extended-gate electrode was miniaturized from 15 to $1.65 \mathrm{~mm}^{2} .^{22}$ Overall, we can conclude that the fabricated OFET is one of the best candidates for flexible and enzymatic biosensors.

\section{Conclusions}

In conclusion, we have successfully demonstrated an enzymatic detection of lactate using a flexible OFET device. In the response to the addition of lactate, changes in the output current of the OFET were observed. This stemmed from the electrochemical reaction of the enzymes on the extended-gate electrode. Notably, the OFET device has several advantages to utilize as a biosensor platform. For example, the OFET device integrated with amplification circuits can improve the sensitivity of biosensors 32,33 in comparison with that of conventional electrochemical-based biosensors. ${ }^{34,35}$ Furthermore, sensing data can be wirelessly sent through OFET-based data transmission circuits. ${ }^{36}$ Hence, we believe that the flexible OFET could pave the way to novel healthcare applications. Our preliminary results suggest that modifications of the flexible
OFET and the use of different enzymes could yield various wearable biosensors. Further development of OFET-based biosensing systems is thus underway in our laboratory.

\section{Acknowledgements}

We gratefully acknowledge the financial support from the Towa Foundation for Food Science and Research, the Kanamori Foundation, the Descente and Ishimoto Memorial Foundation for the Promotion of Sports Science, the Tateishi Science and Technology Foundation, the Society for Research on Umami Taste, and the Japan Society for the Promotion of Science (JSPS, Grant-in-Aid for Scientific Research, Nos. 17 H04882 and 17K14489).

\section{Supporting Information}

This material is available free of charge on the Web at http:// www.jsac.or.jp/analsci/.

\section{References}

1. S. Hanash, Nature, 2003, 422, 226.

2. J. Wang, Chem. Rev., 2008, 108, 814.

3. J. R. Windmiller and J. Wang, Electroanalysis, 2013, 25, 29.

4. C. Crosson and C. Rossi, Biosens. Bioelectron., 2013, 42, 453.

5. N. Islam, F. Shen, P. V. Gurgel, O. J. Rojas, and R. G. Carbonell, Biosens. Bioelectron., 2014, 58, 380.

6. J. Wang, Biosens. Bioelectron., 2006, 21, 1887.

7. H. Sirringhaus, Adv. Mater., 2014, 26, 1319.

8. G. Gelinck, P. Heremans, K. Nomoto, and T. D. Anthopoulos, Adv. Mater., 2010, 22, 3778.

9. V. Subramanian, J. M. J. Fréchet, P. C. Chang, D. C. Huang, J. B. Lee, S. E. Molesa, A. R. Murphy, D. R. Redinger, and S. K. Volkman, Proc. IEEE, 2005, 93, 1330.

10. K. Fukuda, Y. Takeda, M. Mizukami, D. Kumaki, and S. Tokito, Sci. Rep., 2014, 4, 3947.

11. K. Fukuda, Y. Takeda, Y. Yoshimura, R. Shiwaku, L. T. Tran, T. Sekine, M. Mizukami, D. Kumaki, and S. Tokito, Nat. Commun., 2014, 5, 4147.

12. D. Elkington, N. Cooling, W. Belcher, P. C. Dastoor, and X. Zhou, Electronics, 2014, 3, 234.

13. T. Minamiki, T. Minami, R. Kurita, O. Niwa, S. Wakida, K. Fukuda, D. Kumaki, and S. Tokito, Appl. Phys. Lett., 2014, 104, 243703.

14. T. Minamiki, T. Minami, R. Kurita, O. Niwa, S. Wakida, K. Fukuda, D. Kumaki, and S. Tokito, Materials, 2014, 7, 6843.

15. T. Minamiki, T. Minami, Y. Sasaki, R. Kurita, O. Niwa, S. Wakida, and S. Tokito, Anal. Sci., 2015, 31, 725.

16. T. Minami, Y. Sasaki, T. Minamiki, S. Wakida, R. Kurita, O. Niwa, and S. Tokito, Biosens. Bioelectron., 2016, 81, 87.

17. T. Minami, T. Sato, T. Minamiki, and S. Tokito, Anal. Sci., 2015, 31, 721.

18. R. A. Robergs, F. Ghiasvand, and D. Parker, Am. J. Physiol. Regul. Integr. Comp. Physiol., 2004, 287, R502.

19. M. J. Buono, N. V. L. Lee, and P. W. Miller, J. Physiol. Sci., 2010, 60, 103.

20. B. Falk, O. Bar-Or, J. D. MacDougall, L. McGillis, R. Calvert, and F. Meyer, J. Appl. Physiol., 1991, 71, 1735.

21. W. Jia, A. J. Bandodkar, G. Valdés-Ramírez, J. R. Windmiller, Z. Yang, J. Ramírez, G. Chan, and J. Wang, 
Anal. Chem., 2013, 85, 6553.

22. T. Minami, T. Sato, T. Minamiki, K. Fukuda, D. Kumaki, and S. Tokito, Biosens. Bioelectron., 2015, 74, 45.

23. I. Hirata, U. Zschieschang, T. Yokota, K. Kuribara, M. Kaltenbrunner, H. Klauk, T. Sekitani, and T. Someya, Org. Electron., 2015, 26, 239.

24. T. Yamamoto and K. Takimiya, J. Am. Chem. Soc., 2007, 129, 2224.

25. H. Klauk, U. Zschieschang, J. Pflaum, and M. Halik, Nature, 2007, 445, 745.

26. L. B. Goetting, T. Deng, and G. M. Whitesides, Langmuir, 1999, 15, 1182.

27. G. Horowitz, Adv. Mater., 1998, 10, 365.

28. P. Bergveld, Sens. Actuators, B, 2003, 88, 1.

29. T. V. Anh Dam, D. Pijanowska, W. Olthuis, and P. Bergveld, Analyst, 2003, 128, 1062

30. P. J. Derbyshire, H. Barr, F. Davis, and S. P. J. Higson, J. Physiol. Sci., 2012, 62, 429.
31. D. A. Sakharov, M. U. Shkurnikov, M. Y. Vagin, E. I. Yashina, A. A. Karyakin, and A. G. Tonevitsky, Bull. Exp. Biol. Med., 2010, 150, 83.

32. R. Shiwaku, H. Matsui, K. Nagamine, M. Uematsu, T. Mano, Y. Maruyama, A. Nomura, K. Tsuchiya, K. Hayasaka, Y. Takeda, T. Fukuda, D. Kumaki, and S. Tokito, Sci. Rep., 2018, 8, 6368.

33. K. Fukuda, T. Minamiki, T. Minami, M. Watanabe, T. Fukuda, D. Kumaki, and S. Tokito, Adv. Electron. Mater. 2015, $1,1400052$.

34. H. Xia, Y. Kitazumi, O. Shirai, and K. Kano, Anal. Sci., 2017, 33, 839.

35. Y. Matsui, K. Hamamoto, Y. Kitazumi, O. Shirai, and K. Kano, Anal. Sci., 2017, 33, 845.

36. Y. H. Jung, H. Zhang, and Z. Ma, in "Stretchable Bioelectronics for Medical Devices and Systems", ed. J. A. Rogers, R. Ghaffari, and D.-H. Kim, 2016, Springer International Publishing, New York, 83. 